\title{
Adenosine in exhaled breath condensate in healthy volunteers and in patients with asthma
}

\author{
É. Huszár*, G. Vass*, É. Vizi*, Zs. Csoma*, E. Barát*, Gy. Molnár Világos”, I. Herjavecz*, I. Horváth*
}

Adenosine in exhaled breath condensate in healthy volunteers and in patients with asthma. É. Huszár, G. Vass, É. Vizi, Zs. Csoma, E. Barát, Gy. Molnár Világos, I. Herjavecz, I. Horváth. C ERS Journals Ltd 2002.

ABSTRACT: Persistent airway inflammation may require the use of different markers for monitoring airway inflammation. In this study, the authors investigated whether adenosine, which may be produced in allergic inflammatory conditions, could be measured with good reproducibility in exhaled breath condensate (EBC), and whether its concentration was elevated in patients with asthma.

EBC adenosine and exhaled nitric oxide (eNO), a noninvasive marker of asthmatic airway inflammation, were measured in 40 healthy volunteers and 43 patients with allergic bronchial asthma. Repeatability of adenosine measurement was checked in 20 pairs of samples collected from healthy control subjects.

Adenosine was detectable in all EBC samples by the applied high-performance liquid chromatographic method. The mean difference between repeated measurements of adenosine was $-0.1 \mathrm{nM}$ and all differences were within the coefficient of repeatability. Adenosine concentration was higher in steroid-naive patients $(n=23)$ compared with healthy control subjects and steroid-treated patients $(n=20)$. In patients with worsening symptoms of asthma $(n=23)$, adenosine concentration was elevated compared with those in a stable condition $(n=20)$. Furthermore, adenosine concentrations were related to eNO levels in asthmatic patients.

These results, showing good reproducibility of adenosine measurements and increased adenosine concentrations in steroid-naive patients and in patients with worsening of asthmatic symptoms, indicate that adenosine measurement in exhaled breath condensate might be an acceptable novel method to investigate the role of local production of adenosine in the airways.

Eur Respir J 2002; 20: 1393-1398.
*Dept of Pathophysiology and ${ }^{\#}$ Clinical Chemistry, National Korányi Institute for Tuberculosis and Pulmonology, Budapest, Hungary.

Correspondence: É. Huszár, National Korányi Institute for Tuberculosis and Pulmonology, Department of Pathophysiology, Budapest Pihenö ul PO Box 1, H-1529 Hungary.

Fax: 3612007060

E-mail: huszar@koranyi.hu

\section{Keywords: Adenosine}

airway inflammation

bronchial asthma

exhaled breath condensate

exhaled nitric oxide

Received: January 232002

Accepted after revision: July 302002

This study was supported by the Hungarian National Scientific Research Fund (OTKA T-030340) and the Hungarian Ministry of Health Care (ETT T06-160).
Some lines of evidence suggest that adenosine may be produced in asthmatic inflammatory conditions [1]. In patients with asthma, both allergen- and exerciseinduced airway obstruction were related to elevation of adenosine concentration in plasma [2, 3]. Aside from the potential role of adenosine as a mediator of immediate bronchoconstriction [4], this nucleoside may modulate persistent airway inflammation. Adenosine is able to influence leukocyte chemotaxis; it may promote chemotaxis by acting on $\mathrm{A} 2 \mathrm{~b}$ receptors $[5,6]$ or may inhibit chemotaxis by coupling to A2a receptors [7].

Collection of exhaled breath condensate (EBC) has been suggested as a useful sampling method, obtaining mediators directly and noninvasively from the airway surfaces [8]. It was assumed that the highperformance liquid chromatographic (HPLC) method, which was previously developed to measure adenosine in plasma [9], would be suitable to detect adenosine in EBC. In this way, analysis of EBC might provide information about the local concentration of adenosine in the airways.

In the present study, the authors examined whether adenosine could be detected with good repeatability in
EBC and whether its concentration differed between healthy control subjects and patients with allergic bronchial asthma. Elevation in exhaled nitric oxide (eNO) level has been implicated as a potential noninvasive marker of airway inflammation in asthma $[10,11]$. To obtain information about the inflammatory status of the airways, the eNO level was measured in all subjects and its relation to adenosine concentration was investigated.

\section{Methods}

\section{Subjects}

A total of 40 healthy volunteers and 43 asthma patients were studied. All subjects were nonsmokers without significant smoking history. Healthy control subjects were nonatopic, nonasthmatic and without history of any chronic diseases. Patients all met the American Thoracic Society diagnostic criteria for bronchial asthma and they were all sensitised to grass pollen. In 41 of the 43 patients, additional allergic sensitisation to house dust mite, dog or cat 
Table 1. - Subjects' characteristics

\begin{tabular}{|c|c|c|c|}
\hline & $\begin{array}{l}\text { Healthy } \\
\text { control }\end{array}$ & $\begin{array}{l}\text { Steroid } \\
\text { naive }\end{array}$ & $\begin{array}{l}\text { Steroid } \\
\text { treated }\end{array}$ \\
\hline Subjects $n$ & 40 & 23 & 20 \\
\hline Sex F:M & $26: 14$ & $11: 12$ & $8: 12$ \\
\hline Age yrs & $32(28-35)$ & $33(27-38)$ & $35(29-41)$ \\
\hline $\mathrm{BDP} \mu \mathrm{g}$ & & & $1246(927-1565)$ \\
\hline FEV1\% & 91 (87-94) & 85 (81-89)* & $82(77-86)^{* *}$ \\
\hline $\begin{array}{l}\text { Asthmatic } \\
\text { symptoms }{ }^{\#} \mathrm{n}\end{array}$ & & 17 & 6 \\
\hline
\end{tabular}

Data are presented as mean (95\% confidence interval). F: females; M: male; BDP: daily dose of inhaled steroids as beclomethasone dipropionate equivalents; FEV1: forced expiratory volume in one second. \#: recent worsening of. *: $\mathrm{p}<0.05$ versus healthy controls; **: $\mathrm{p}<0.01$ versus healthy controls.

dander was observed (skin-prick tests with Soluprick; ALK, Abello Copenhagen, Denmark). Asthmatic subjects were all studied in the grass pollen season after visiting the outpatient clinic. Some of them experienced recent worsening of asthmatic symptoms (decrease in exercise tolerance, wheezing or awakening during the night because of breathlessness). Steroidnaive $(\mathrm{SN})$ patients received only short-acting inhaled $\beta_{2}$-agonists as needed. Medication of steroid-treated (ST) patients was limited to inhalation of corticosteroids and short-acting $\beta_{2}$-agonists. Table 1 shows characteristics of patients and healthy control subjects. The local ethics committee approved the protocol and written informed consent was obtained from each subject before the study.

\section{Study design}

All subjects were instructed to refrain from caffeinecontaining beverages and exercise. Patients were asked to refrain from using bronchodilators for at least $8 \mathrm{~h}$ before the study. Twenty healthy control subjects took part in the repeatability study. Samples were collected from them at the same time on two successive days. Amylase activity in EBC samples was determined to investigate if saliva significantly contaminated the condensate. Furthermore, adenosine concentrations were measured in saliva and compared to that in matched EBC samples (15 healthy controls and 10 asthmatic subjects), to assess the possible effect of saliva contamination on adenosine concentration in EBC. All subjects' details were obtained and eNO level and forced expiratory volume in one second (FEV1) values were measured, followed by collection of EBC at 09:00 h.

\section{Lung function test and exhaled nitric oxide measurement}

FEV1 was measured by means of an electronic spirometer (MS-11; MEDICOR, Budapest, Hungary) and was expressed as percentage of the predicted normal value for the subjects' height and age, according to European Coal and Steel Community reference values. The best of three consecutive manoeuvres was accepted for evaluation.

To measure eNO, a chemiluminescence analyser (Model LR2000; Logan Research, Rochester, UK), sensitive to NO from 1-5,000 parts per billion (ppb) by volume and with a resolution of $0.3 \mathrm{ppb}[10,12]$, was used. The analyser was designed for online recording of eNO concentrations. It was calibrated with a certified NO mixture $(90 \mathrm{ppb})$ in nitrogen (BOC Special Gases, Guildford, UK). Measurement of eNO was made by slow exhalation $\left(5-6 \mathrm{~L} \cdot \mathrm{min}^{-1}\right)$ from total lung capacity for 20-30 s against a resistance $(0.4 \pm 0.05 \mathrm{kPa}(3.0 \pm 0.4 \mathrm{mmHg}))$, to prevent nasal contamination, according to the current European Respiratory Society guidelines [12].

\section{Collection of expired breath condensate and saliva}

EBC was collected using an EcoScreen condenser (Jaeger, Hoechberg, Germany) by a method previously published [13]. Subjects breathed through a mouthpiece and a two-way, nonrebreathing valve, which also served as a saliva trap. Subjects were asked to breathe at a normal frequency and tidal volume, wearing a noseclip for a period of $10 \mathrm{~min}$. Mean expiratory flow rates were $210-350 \mathrm{~mL} \cdot \mathrm{s}^{-1}$ both in healthy control subjects and in asthmatic patients, with no significant difference between the groups. To obtain saliva samples, subjects chewed dental tampons for 1-2 min immediately after collection of breath condensate. Saliva was collected from tampons by centrifugation (at $0^{\circ} \mathrm{C}$ and $1,000 \times g$ for $10 \mathrm{~min}$ ).

Condensate samples were tested for salivary amylase using an enzymatic colorimetric kinetic method (Reanal Finechemical Co., Budapest, Hungary) with Olympus AU 400 Automate (Olympus Optica Co., Mishima, Japan).

\section{Determination of adenosine}

Both the condensate and saliva samples were deproteinised by ultrafiltration and then analysed by HPLC immediately [9]. Adenosine concentration was measured six times from the same ultra-filtered EBC samples to check the intra-assay coefficient of variation (CV) of the analytical method. Recovery of ultrafiltration for adenosine was determined in spiked samples at three different concentrations. Stability was assessed in four samples, with adenosine concentration at $5.2-38.5 \mathrm{nM}$, after storage for $4 \mathrm{~h}$ at room temperature.

\section{Statistical analysis}

FEV1 values, adenosine concentration and eNO levels were expressed as mean and 95\% confidence intervals. Comparisons between groups were performed by parametric t-test because data showed normal distribution. Recovery of ultrafiltration and 
stability of adenosine were calculated by:

$$
\text { Recovery } \%=100 \times
$$

(adenosine in spiked - adenosine in native) sample adenosine standard

$$
\text { Stability } \%=100 \times \frac{\text { adenosine after } 4 \mathrm{~h}}{\text { adenosine at time } 0}
$$

Correlations between the variables were calculated by Pearson's product moment correlation test. Differences were considered significant at $p<0.05$. BLAND and Altman's [14] test was used to assess repeatability of adenosine measurement in EBC.

\section{Results}

The detection limit, defined as the lowest concentration of adenosine resulting in a signal-to-noise ratio of 3 , was $2 \mathrm{nM}$ of adenosine. Adenosine concentration was $\geqslant 2 \mathrm{nM}$ in all EBC samples.

The intra-assay CV of the HPLC method was 8.4 and $4.9 \%$, at 11 and $20 \mathrm{nM}$ of adenosine, respectively. In the samples, spiked with 10,20 and $30 \mathrm{nM}$ of adenosine standards, recoveries of ultrafiltration were 98, 92.5 and 98\%, respectively. Stability of adenosine in one native and three spiked samples was 93-106\% during $4 \mathrm{~h}$ storage at room temperature (table 2).

The repeated determination of adenosine in healthy control subjects showed good repeatability in EBC. Adenosine concentrations $(n=20)$ on day 1 and on day 2 were $8.8 \mathrm{nM}$ (range 5.9-11.7 $\mathrm{nM}$ ) and $8.9 \mathrm{nM}$ (range 6.1-11.7 $\mathrm{nM}$ ), respectively. The mean difference with coefficient of repeatability was $-0.1 \pm 3.6 \mathrm{nM}$ and all differences were within $\pm 2 \mathrm{SD}$ (fig. 1a). The correlation between adenosine concentrations measured on two consecutive days was significant (fig. 1b).

Adenosine concentrations were $\sim 10$ times higher in saliva than in EBC samples, with no significant difference between healthy control subjects (162 nM, range $108-216, \mathrm{n}=15)$ and asthmatic patients $(181 \mathrm{nM}$, range $105-257 ; \mathrm{n}=10$ ). Adenosine concentrations, measured in EBC and matched saliva samples, did not correlate (correlation coefficient $(r)=-0.05$, $\mathrm{p}=0.818, \mathrm{n}=25)$. There were only five $\mathrm{EBC}$ samples with measurable amylase activity $\left(8 \mathrm{U} \cdot \mathrm{L}^{-1}\right.$, range $0.1-15.5, n=5]$. Salivary amylase activity checked in two control subjects was $>10^{5} \mathrm{U} \cdot \mathrm{L}^{-1}$.

In $\mathrm{SN}$ patients, adenosine concentrations were

Table 2. - Stability of adenosine

\begin{tabular}{rrr}
\hline \multicolumn{2}{c}{ Adenosine concentration $\mathrm{nM}$} & Stability \% \\
\hline T0 & $\mathrm{T} 4$ & \\
\hline 5.2 & 5.5 & 106 \\
13.5 & 12.5 & 93 \\
25.0 & 23.5 & 94 \\
38.5 & 38.8 & 102 \\
\hline
\end{tabular}

T0: immediately after ultrafiltration of samples; T4: after $4 \mathrm{~h}$ storage of samples at room temperature.
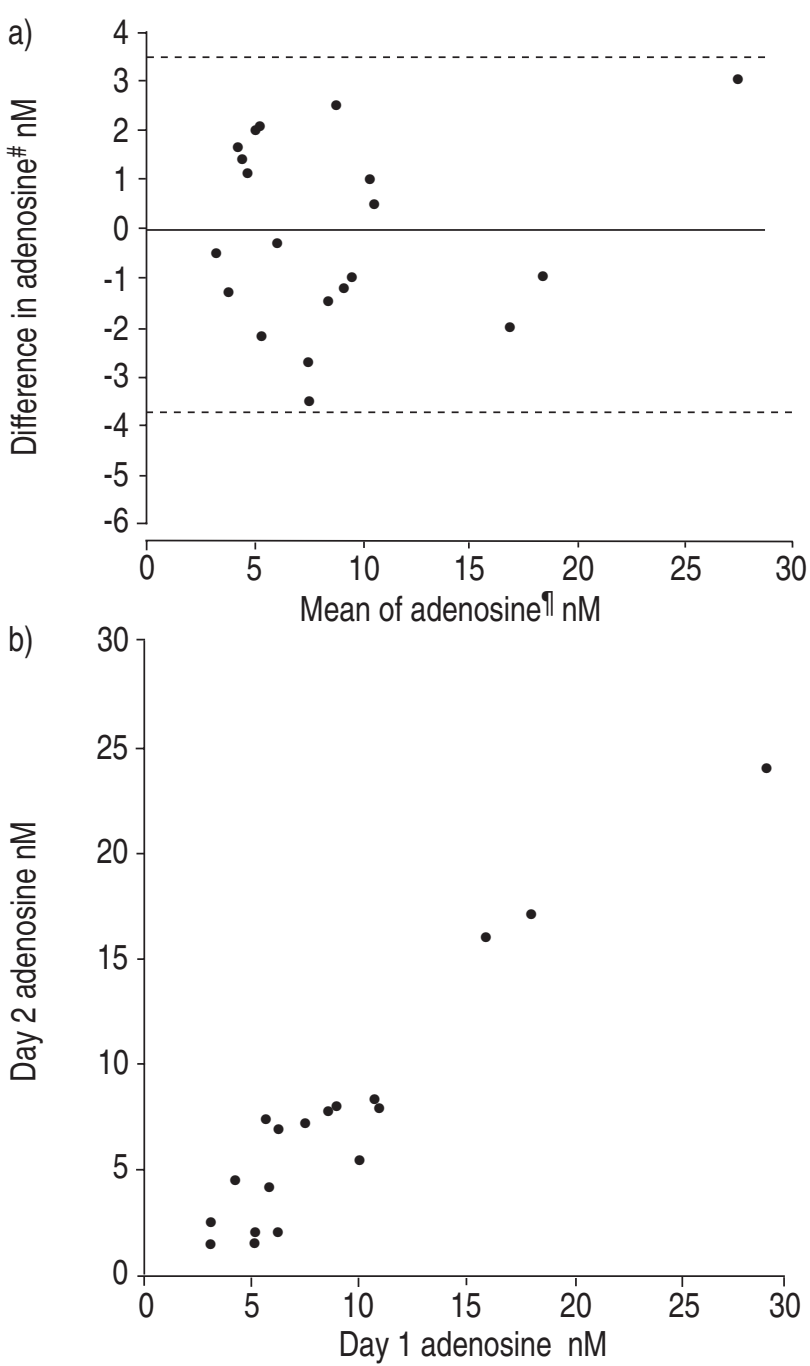

Fig. 1.-Day-to-day repeated measures in healthy control subjects $(n=20)$. a) Differences against means for adenosine values. \#. difference in adenosine concentrations for each pair of condensate samples (collected from the same individuals on day 1 and day 2); ๆ: average concentrations of adenosine for each pair of condensate samples (collected from the same individuals on day 1 and day 2). -: mean adenosine value; - - -: $\pm 2 \mathrm{SD}$ values. b) Correlation between adenosine concentrations measured in the same individuals on day 1 and day 2 (correlation coefficient $=0.953 ; \mathrm{p}<0.001$ ).

significantly elevated (15 $\mathrm{nM}$, range $12-18)$ compared with healthy control subjects $(9 \mathrm{nM}$, range 7-11) and ST patients (10 nM, range 8-13). No significant difference in adenosine concentrations between healthy control subjects and ST asthmatic patients was found (fig. 2a). Levels of eNO were significantly elevated in both SN patients (21.3 ppb, range 15.2-27.4) and ST patients $(9.1 \mathrm{ppb}$, range 7.0-11.2) compared with healthy control subjects (3.9 ppb, range 3.4 4.4), and there was a significant difference in eNO between $\mathrm{SN}$ and ST patients (fig. 2b).

Significant differences were found both in adenosine and eNO concentrations, but not in FEV1 values between patients with and without worsening of asthmatic symptoms (table 3 ).

There was a statistically significant positive correlation between adenosine concentrations and eNO 

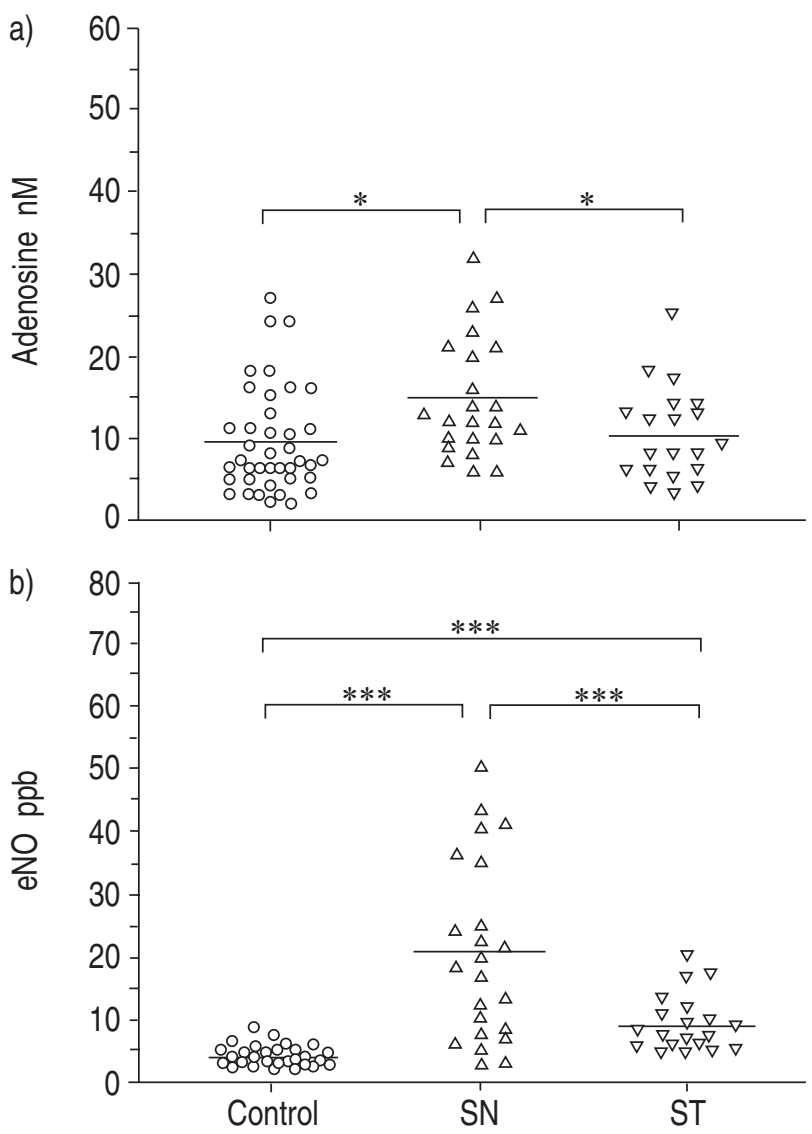

Fig. 2. - Individual and mean (-) values of a) adenosine concentrations and b) exhaled nitric oxide (eNO) levels for control $(\bigcirc$; $\mathrm{n}=40)$, steroid-naive $(\mathrm{SN})$ patients with allergic bronchial asthma $(\triangle ; \mathrm{n}=23)$ and steroid-treated $(\mathrm{ST})$ patients with allergic bronchial asthma $(\nabla ; \mathrm{n}=20) . *$ : $\mathrm{p}<0.05 ; * * *: \mathrm{p}<0.001$.

levels in asthmatic patients $(\mathrm{r}=0.399, \mathrm{p}<0.01, \mathrm{n}=43$; fig. 3). FEV1 values did not correlate with adenosine concentrations and eNO levels in any groups.

\section{Discussion}

In this study, good repeatability for adenosine measurements in EBC was found and elevated concentrations of adenosine in $\mathrm{SN}$ asthmatic patients and patients with worsening asthmatic symptoms were observed.

Table 3. - Patients with and without worsening of asthmatic symptoms

\begin{tabular}{lcc}
\hline & With & Without \\
\hline Patients n & 23 & 20 \\
SN/ST & $17 / 6$ & $6 / 14$ \\
FEV1 \% & $84(80-88)$ & $83(79-87)$ \\
eNO ppb & $19.1(13.1-25.2)^{*}$ & $11.6(7.6-15.7)$ \\
Adenosine nM & $15.5(12.4-18.5)^{* *}$ & $9.5(7.1-11.8)$ \\
\hline
\end{tabular}

Data are presented as mean (95\% confidence interval). SN: steroid-naive asthmatic patients; ST: steroid-treated asthmatic patients; FEV1: forced expiratory volume in one second; eNO: exhaled nitric oxide; ppb: parts per billion. $*: \mathrm{p}<0.05$ between groups; **: $\mathrm{p}<0.01$ between groups.

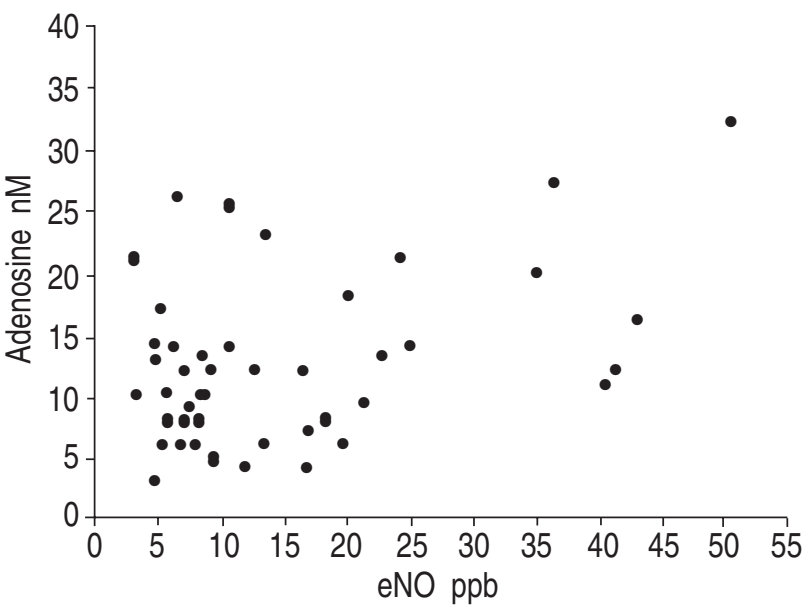

Fig. 3.-Correlation between adenosine concentrations and exhaled nitric oxide (eNO) levels in asthmatic patients (correlation coefficient $=0.399, \mathrm{n}=43, \mathrm{p}<0.01)$.

To obtain information about the role of different mediators in the airways, analysis of EBC samples were suggested to be a useful, direct and noninvasive method. Therefore, in this study a previously developed HPLC method for adenosine measurement in plasma was adjusted to measure adenosine in EBC. When adenosine was measured in plasma, a so-called stop solution was applied to prevent in vitro changes of adenosine concentration in blood samples. EBC, unlike plasma, contains cells and/or proteins in very low concentrations. Furthermore, collection of EBC samples occurred at $-20^{\circ} \mathrm{C}$. Therefore, it was surmised that the use of inhibitors was unnecessary to prevent in vitro changes of adenosine concentration in EBC. In this study, the recovery and stability of adenosine was measured in four samples in the absence of any inhibitors, within the range representative for adenosine concentration of examined subjects. It was found that an adenosine concentration of $5.2-38.5 \mathrm{nM}$ produced $>90 \%$ recovery and stability.

The observation that amylase activity, which was detected in only five samples, was low in EBC compared with saliva $\left(1: 1 \times 10^{4}\right)$ indicated that contamination being caused by salivary adenosine was not likely to influence the results on adenosine concentrations in EBC.

Any process which needs energy consumption and concomitant adenosine triphosphate degradation may increase adenosine concentration. To decrease this "biological" change in adenosine concentrations, which may occur during daily activities of subjects, all breath condensate samples were collected in the morning. EBC was collected in a series of healthy control subjects at 09:00 h on two consecutive days, resulting in good repeatability for adenosine measurement in EBC. Owing to the fact that adenosine concentrations were within the same range in healthy control subjects and asthmatic patients, repeatability of adenosine measurements in asthmatic patients was not examined separately. However, before designing prospective studies, which include repeated adenosine measurements, the intra-individual variability of 
adenosine measurement needs to be analysed rigorously in patients.

SCHLEISS et al. [15] demonstrated that the exhaled hydrogen peroxide level was flow-dependent at expiratory flow rates between $48-140 \mathrm{~mL} \cdot \mathrm{s}^{-1}$. Taking into consideration the fact that the curve they found showed flatness at higher flow rates, they concluded that it was unlikely that flow dependence had markedly biased the results of studies performed with normal tidal breathing. In the present study, tidal breathing was performed for the collection of $\mathrm{EBC}$ with mean expiratory flow rates between $210-350 \mathrm{~mL} \cdot \mathrm{s}^{-1}$ in all subjects, without significant difference between healthy control subjects and asthmatic patients. Therefore, it was assumed that the differences in individual flow rates did not have a considerable influence on adenosine concentrations in EBC.

Elevation in adenosine concentrations and also in eNO levels in $\mathrm{SN}$ patients indicated that there might be an increase in the number and/or sensitivity of inflammatory cells in the airways. The lack of difference in adenosine concentrations between ST patients and healthy control subjects and the significantly lower adenosine concentrations and eNO levels in ST in comparison with SN patients might be a consequence of anti-inflammatory effects of steroid treatment. The higher eNO levels observed in ST patients rather than in healthy control subjects, however, indicated that steroid treatment could not control the airway inflammation entirely. This might be explained by the fact that all patients were studied during pollen season when allergen exposure could worsen inflammation in the airways, despite steroid treatment.

In asthmatic patients a weak correlation was found between adenosine concentrations and eNO levels. However, the different range of eNO levels, but not adenosine concentrations, in healthy control subjects and asthmatic patients, and the different patterns of these two inflammatory metabolites observed in the ST group, indicated that EBC adenosine and eNO may reflect different aspects of asthmatic airway inflammation. This observation is in line with previous findings showing discrepancies between different markers of asthma, including airway hyperresponsiveness, sputum eosinophils and eNO levels, suggesting that these markers may provide different information when monitoring asthmatic airway inflammation [16-18]. In this respect, EBC adenosine may provide additional information when monitoring the disease.

In this study, steroid treatment caused a decrease in the level of both inflammatory mediators, but only adenosine concentration fell to control level in ST patients. The difference between the two mediators may be a consequence of various sources of adenosine and NO. Some lines of evidence show that adenosine is mostly released from activated mast cells [19, 20]. Lack of elevated adenosine concentration in ST patients may reflect that inhaled steroid treatment could reduce number and/or activation of mast cells in the airways. This assumption is based on the results of a previous study, which proved that 6 weeks of treatment with inhaled corticosteroid could markedly reduce the number of mast cells in the bronchial mucosa [21]. At the same time, eNO level was linked with sputum eosinophil counts in asthmatic patients $[11,22]$. Eosinophils are able to express the inducible NO synthase and produce NO [23]. TRIGG et al. [24] found persisting eosinophilic inflammation in bronchial (sub)mucosa after long-term inhaled steroid treatment in some asthmatic patients. If this occurred in the present study, it could be one of the contributing factors resulting in elevated eNO levels in ST patients. Furthermore, airway epithelial cells also express inducible NO synthase, and increased NO production by inducible NO synthase in these cells may also contribute to the elevation of eNO level in the asthmatic airways [25-27].

In conclusion, the findings of this study show that adenosine measurement in exhaled breath condensate is reproducible and that adenosine concentration is elevated in steroid-naive asthmatic patients and in patients with worsening of asthma symptoms. Considering that adenosine concentrations were of similar ranges in healthy control subjects and in asthmatic patients, the authors do not think that it is possible to use adenosine concentrations in exhaled breath condensate as a diagnostic tool for allergic bronchial asthma. However, significant elevation in adenosine concentrations in patients with worsening of asthmatic symptoms raises the possibility that measurement of adenosine in exhaled breath condensate may be a valuable method to obtain information on ongoing airway inflammation. Furthermore, prospective studies are needed to examine whether during exacerbation of asthma, and possibly other types of chronic inflammation (e.g. chronic obstructive pulmonary disease and cystic fibrosis), adenosine formation might be facilitated. To confirm the potential use of adenosine concentration in exhaled breath condensate for the monitoring of either chronic or acute airway inflammation further studies are needed.

Acknowledgement. The authors would like to thank R. Nagy and M. Czok for lung function measurements, and M. Hernádi, M. Mikoss and M. Kenéz for the collection and processing of breath condensate and saliva samples.

\section{References}

1. Driver AG, Kukoly CA, Ali A, Mustafa SJ. Adenosine in bronchoalveolar lavage fluid in asthma. Am Rev Respir Dis 1993; 15: 161-165.

2. Mann JS, Holgate ST, Renwich AG, Cushley MJ. Airway effects of purine nucleosides and nucleotides and release with bronchial provocation in asthma. J Appl Physiol 1986; 61: 1667-1776.

3. Vizi É, Huszár É, Csoma Zs, et al. Plasma adenosine concentration increases during exercise: a possible contributing factor to exercise-induced bronchoconstriction in asthma. J Allergy Clin Immunol 2002; 109: 446-448.

4. Huszár É, Horváth I, Barát E, Herjavecz I, Böszörmény-Nagy G, Kollai M. Elevated circulating 
adenosine level potentiates antigen-induced immediate bronchospasm and bronchoconstrictor mediator release in sensitized guinea pigs. J Allegy Clin Immunol 1998; 102: 687-691.

5. Feoktistov I, Biaggioni I. Adenosine A2b receptors evoke IL-8 secretion in human mast cells. $J$ Clin Invest 1995; 138: 1979-1986.

6. Rose FR, Hirshhorn R, Weissman G, Cronstein BN. Adenosine promotes neutrophil chemotaxis. $J$ Exp Med 1988; 167: 1186-1194.

7. Flamand N, Boudreault S, Picard S, et al. Adenosine, a potent natural suppressor of arachidonic acid release and leukotriene biosynthesis in human neutrophils. Am J Respir Crit Care Med 2000; 161: S88-S94.

8. Kharitonov SA, Barnes PJ. Exhaled markers of pulmonary disease. Am J Respir Crit Care Med 2001; 163: 1693-1722.

9. Huszár É, Barát E, Kollai M. Isocratic highperformance liquid chromatographic determination of plasma adenosine. Chromatographia 1996; 42: 318-322.

10. Kharitonov SA, Barnes PJ. Clinical aspects of exhaled nitric oxide. Eur Respir J 2000; 16: 781-792.

11. Horváth I, Donelly LE, Kiss A, et al. Combined use of exhaled hydrogen peroxide and nitric oxide in monitoring asthma. Am J Respir Crit Care Med 1998; 158: 1042-1046.

12. Kharitonov SA, Alving K, Barnes PJ. Exhaled and nasal nitric oxide measurements: recommendations. Eur Respir J 1997; 10: 1683-1693.

13. Montuschi P, Collins JV, Ciabattoni G, et al. Exhaled 8 -isoprostane as an in vivo biomarker of lung oxidative stress in patients with COPD and healthy volunteers. Am J Respir Crit Care Med 2000; 162: 1175-1177.

14. Bland JM, Altman DG. Statistical method for assessing agreement between two methods of clinical measurement. Lancet 1986; 1: 307-310.

15. Schleiss MB, Holz O, Behnke M, Richter K, Magnuessen H, Jorres RA. The concentration of hydrogen peroxide in exhaled air depends on expiratory flow rate. Eur Respir J 2000; 16: 1115-1118.

16. van Rensen EL, Straathof KC, Veselic-Charvat MA, Zwinderman AH, Bel EH, Sterk PJ. Effect of inhaled steroids on airway hyperresponsiveness, sputum eosinophils, and exhaled nitric oxide levels in patients with asthma. Thorax 1999; 54: 403-408.
17. van den Toorn LM, Overbeek SE, de Jongste JC, Leman K, Hoogsteden HC, Prins JB. Airway inflammation is present during clinical remission of atopic asthma. Am J Respir Crit Care Med 2001; 164: 2107-2113.

18. Alvarez MJ, Olaguibel JM, Acero S, Garcia BE, Tabar AI, Urbiola E. Effect of current exposure to Der p1 on asthma symptoms, airway inflammation, and bronchial hyperresponsiveness in mite-allergic asthmatics. Allergy 2000; 55: 185-190.

19. Marquardt DL, Gruber HE, Wasserman SI. Adenosine release from stimulated mast cells. Proc Natl Acad Sci USA 1984; 81: 192-196.

20. Pauwels R. The role of adenosine in bronchial asthma. Bull Eur Physiopathol Respir 1987; 23: 203-208.

21. Djukanovič R, Wilson JW, Britten KM, et al. Effect of fan inhaled corticosteroid on airway inflammation and symptoms in asthma. Am Rev Respir Dis 1992; 145: 669-674.

22. Payne DN, Adcock IM, Wilson NM, Oates T, Scallan M, Bush A. Relationship between exhaled nitric oxide and mucosal eosinophilic inflammation in children with difficult asthma, after treatment with oral prednisolone. Am J Respir Crit Care Med 2001; 164: 1376-1381.

23. del Pozo V, de Arruda-Chaves E, de Andres B, et al. Eosinophils transcribe and translate messenger RNA for inducible nitric oxide synthase. J Immunol 1997; 158: 859-864.

24. Trigg CJ, Manolitsas ND, Wang J, et al. Placebocontrolled immunopathologic study of four months of inhaled corticosteroids in asthma. Am J Respir Crit Care Med 1994; 150: 17-22.

25. Redington AE, Meng QH, Springall DR, et al. Increased expression on inducible nitric oxide synthase and cyclo-oxygenase- 2 in the airways epithelium of asthmatic subjects and regulation by corticosteroid treatment. Thorax 2001; 56: 351-357.

26. Ricciardolo FL, Timmers MC, Geppetti $\mathrm{P}$, et al. Allergen-induced impairment of bronchoprotective nitric oxide synthesis in asthma. $J$ Allergy Clin Immunol 2001; 108: 198-204.

27. Donelly LE, Barnes PJ. Expression and regulation of inducible nitric oxide synthase from human primary airway epithelial cells. Am J Respir Cell Mol Biol 2002; 26: $144-151$. 